\title{
Joubert Sendromu Tanısı Alan Yenidoğan: Olgu Sunumu
}

\section{Newborn Diagnosed with Joubert Syndrome: A Case Presentation}

\author{
Muhammet Bulut ${ }^{1}$, Dilek Küçük Alemdar²* \\ ${ }^{1}$ Giresun Üniversitesi Tıp Fakültesi, Çocuk Sağlığı ve Hastalıkları AD Giresun, Türkiye \\ ${ }^{2}$ Giresun Üniversitesi Sağlık Bilimleri Fakültesi, Çocuk Sağlığı ve Hastalıkları Hemşireliği AD \\ Giresun/Türkiye \\ e-mail: dilekkucuk@atauni.edu.tr \\ ORCID: 0000-0002-5963-1267 \\ ORCID: 0000-0002-7275-0666 \\ *Sorumlu Yazar / Corresponding Author: Sorumlu Yazar: Dilek Küçük Alemdar²
}

Gönderim Tarihi / Received: 14.11.2019

Kabul Tarihi / Accepted: 07.05.2020

DOI: $10.34087 /$ cbusbed.646787

\begin{abstract}
Erken membran rüptürü nedeniyle 36. Gebelik haftasında doğan erkek bebek, doğum sonrası 1. dakika APGAR ‘ 18 , 5. dakika APGAR '1 9 olarak kaydedildi. Anne yanı izlemlerinde beslenirken siyanozu olması nedeniyle postnatal 19. saatinde yenidoğan yoğun bakım ünitesine alındı. Hastanın solunum sesleri dinlemekle her iki hemitoraksta doğal olmasına rağmen inter kostal ve subkostal çekilmeleri mevcuttu. Non-invaziv ventilasyon desteği altında dirençli apnelerinin olması üzerine entübe edilerek mekanik ventilatöre bağlandı. Kraniyal MR 'ında; disorganize, disgenetik, split serebellar vermis; kalın superior serebellar pedinkül ve küçük inferior serebellar pedinküllerden oluşan 'molar diş' görünümü izlendi. Kliniğimizde takipte olduğu süre içerisinde hiperpne-apne atakları belirli aralarla tekrarlayan ve iki kez klonik konvülsiyonu gözlenen hastaya $5 \mathrm{mg} / \mathrm{kg} / \mathrm{gün}$ fenobarbital tedavisi uygulandı. $\mathrm{Bu}$ bulgular 1şı̆̆ında klinik tablosu ve kranial MR değerlendirmesiyle bebeğe Joubert Sendromu tanısı konuldu. Yenidoğan yoğunbakım ünitesinde genel durumunu bozmayan hiperpne-apne periyotları ara ara devam etti. 28 günlük takip ve tedavi sonunda anne uyumu tamamlanan bebek çocuk nöroloji takipleri yapılmak üzere önerilerle taburcu edildi.
\end{abstract}

Anahtar Kelimeler: Joubert Sendromu, yenidoğan, olgu sunumu

\begin{abstract}
The APGAR score of male infant born at the 36th gestational week due to an early membrane rupture, was recorded as 8 in the postnatal 1 st minute and 9 in the postnatal 5 th minute. During the mother-side follow-ups he was taken to the neonatal intensive care unit in the postnatal 19th hour due to having cyanosis while feeding. The patient's respiratory sounds were listened to and it was determined that there were intercostal and subcostal withdrawals in both hemithoraxes, though natural. Due to the presence of resistant apnea under non-invasive ventilation support, he was intubated and put on a mechanic ventilator. In his cranial MR; a disorganized, disgenetic 'molar tooth' appearance producing split cerebellar and consisting of thick superior cerebellar peduncles and small inferior cerebellar peduncles, was observed. A five $\mathrm{mg} / \mathrm{kg} / \mathrm{day}$ phenobarbital treatment was applied to the patient, who had repetitive hyperpnea-apnea attacks at certain intervals and was observed to have clonic convulsions twice during his follow-up in our clinic. In the light of these findings; the infant was diagnosed with Joubert Syndrome according to his clinical picture and cranial MR evaluation. His hyperpnea-apnea attacks continued at intervals without destroying his general condition in the neonatal intensive care unit. At the end of the 28-day follow-up and treatment, the infant who completed his mother adaptation was discharged to have pediatric neurological follow-ups with recommendations.
\end{abstract}

Key Words: Joubert Syndrome, newborn, case presentation 


\section{Giriş}

Joubert sendromu (JS), serebellar vermis hipoplazisi, hipotoni, anormal solunum paterni, göz hareket bozuklukları, ataksi, mental gerilik ve gelişme geriliği ile karakterize otozomal resesif geçişli nadir görülen bir sendromdur [1,2]. İlk kez 1969 yılında Fransız nörolog Marie Joubert tarafindan tanımlanan bu sendromda nöroradyolojik olarak molar diş görünümü karakteristiktir. Çoğu JS vakası sporadiktir; ancak bazı ailelerde JS resesif geçiş göstermektedir. Son zamanlarda yapılan araştırmalarda spesifik genin 6q23.2-q23.3 kromozomunda yer aldığ 1 belirtilmektedir [3]. Ortalama tanı yaşının 33 ay olduğu bu sendromda yenidoğan döneminde tanı daha az siklıkla konur. Yenidoğan döneminde klinik bulgu olarak santral apneyle birlikte olan hiperpne vardır $[1,2,3]$. İleri yaşlarda okul başarısında gecikme ile özel eğitim gerektiren hastalar olabileceği gibi normal zeka seviyesinde de olabilirler $[1,2]$.

JS'da nörolojik sistem bulguları haricinde; polidaktili, damak-dudak anormallikleri, dil anormallikleri, ensefalosel, meningosel, böbrek anomalileri eşlik edebilir [4]. Radyolojik ve nöropatolojik çalışmalarda gözlenen merkezi sinir sistemi malformasyonu spektrumu, JS'nin birçok klinik özelliğini barındırmaktadır. Aksiyal plan MR (Manyetik Rözonans) görüntülemelerinde molar diş, hipoplastik/aplastik serebellar vermis, kalın uzamış superior serebellar pedinkül, derin posterior interpedinküler fossa görünümü JS hastalarının $\% 85$ 'inde izlenir [5]. JS tedavisi semptomatik ve destekleyici tedavilerdir. Prognoz serebellar vermisin hipoplastik ya da aplastik oluşuna bağlıdır [4].

$\mathrm{Bu}$ olgu sunumumuzda yenidoğan döneminde anne yanı izlemlerinde vizit sırasında fark ettiğimiz, monitorize izlemlerinde klinik ve görüntüleme ile tanı koyduğumuz detaylı anamnezinde kardeş öyküsünde de JS olan bir vakamızı sunduk.

\section{Olgu}

Erken membran rüptürü nedeniyle 36. gebelik haftasında doğan erkek bebek, doğum sonrası 1. dakika APGAR '1 8, 5. dakika APGAR '1 9 olarak kaydedildi. Anne ve baba arasında 2. dereceden akraba evliliği mevcut olup 3 çocuğundan ikisi sağlıklı, çocuklarından birinde genetik hastalık olduğu ve takiplerinde sorun yaşanmadıkları öğrenildi. Anne yanı izlemlerinde beslenirken siyanozu olması nedeniyle postnatal 19 . saatinde yenidoğan yoğun bakım ünitesine alındı. Monitorize edilen ve IV sıvısı başlanan hastanın çekilen akciğer grafisinde kliniğini açıklayacak patolojiye rastlanılmadı. Fizik muayenesinde; bilinç açık, hipotonik, ateş $36,5^{\circ} \mathrm{C}$ (aksiller), nabız 130/dk ritmik, solunum sayıs1 80/dk olan hastanın ağirlı̆̆ $3500 \mathrm{~g}(50$ 75. persentil), baş çevresi $37 \mathrm{~cm}$ (90. persentil), boyu 51 cm (50-75. persentil) olarak ölçüldü. Göz muayenesinde 1ş1k refleksi bilateral pozitif, her iki göz ön segment ve fundusu doğal ve kırmızı refle testi normal olarak değerlendirildi. Ayrıca fizik muayenesinde kepçe kulak ve frontal belirginleşme mevcuttu. Kliniği ile uyumsuz takipnesi olduğu saptanan bebek, non-invaziv ventilasyona alındı. Bebeğin çekilen EKO (Ekokardiyografi)' sunda küçük ASD (Atrial Septal Defekt) ve PFO (Patent Foramen Ovale) olduğu saptand 1 ve bu sebeple 2 ay sonra kontrol önerildi. Monitorize izlemlerinde 20 saniyeden uzun süren apneleri olması üzerine kafein sitrat tedavisi başlandı, non-invaziv ventilasyona devam edildi. Kranial ultrasonunda anormallik saptanmadi. Yapılan laboratuar incelemesinde; Lökosit: 23000/ $\mathrm{mm}^{3}$, MNS: 14500 , lenfosit: 7300 , trombosit 237.000/ $\mathrm{mm}^{3}$, hgb: $18.3 \mathrm{~g} / \mathrm{dl}$, hematokrit: \%56, serum glukozu: $57 \mathrm{mg} / \mathrm{dl}$, elektrolit değerlerinde hafif hipernatremisi haricinde normaldi. Böbrek ve karaciğer fonksiyon testleri normal saptand1. Sepsis açısından bakılan CRP 1,5 mg/dl saptandı. Bunun yanı sira emmesinin azalması ve hipotonitesinin gelişmesi ve akut faz reaktanlarının artması üzerine erken sepsis ön tanısı ile (kültür pozitifliği olmadığı için kesin tanı koyulamad1) hastaya ampisilin ve gentamisin tedavisi başlandi. Alınan kan, idrar ve BOS mikrobiyolojik incelemesi normal saptand. BOS glukoz ve proteinin normal olduğu saptandi. Ventilasyon desteği altında dirençli apnelerinin olması üzerine entübe edilerek mekanik ventilatöre bağlandı. Entübe edilen bebeklerde, gerek hasta konforu, gerekse de ventilasyona hasta uyumunun sağlanması için düşük dozda fentanil infüzyonu, tüm yenidoğan kliniklerinde uygulanan bir protokol olması nedeniyle hastamıza sedasyon başlandı. Mekanik ventilatör izlemlerinde minimal parametrelerde kan gazları alkalotik seyreden hastanın metabolik tetkikleri gönderildi. İkinci gününde ekstübe edilen ve nazal CPAP (Continious Positive Airway Pressure) ile takip edilmeye başlanan hastanın solunum paterninin hiperpne sonrasında solunum durması şeklinde olduğu görülmesi üzerine kranial görüntüleme yapıldı. Kranyal MR'sinde; disorganize, disgenetik, split serebellar vermis; kalınsuperior serebellar pedinkül ve küçük inferior serebellar pedinküllerden oluşan 'molar diş' görünümü ve korpus kallosum agenezisi izlendi (Resim 1 ve 2). Kliniğimizde takipte olduğu süre içerisinde hiperpne-apne atakları tekrarlayan ve iki kez klonik konvülsiyonu gözlenen hastaya $5 \mathrm{mg} / \mathrm{kg} /$ gün fenobarbital tedavisi uyguland1. Yoğunbakım izlemlerimizde 2 gün entübasyon sonrasında bebek 20 gün nasal CPAP da izlendi. Yatışının 4.gününde yapılan EEG (Elektroensefalografi)' si normal olarak değerlendirildi. Metabolik taramalarında patoloji saptanmadı. Bu bulgular 1şı̆̆ında klinik tablosu ve kranial MR değerlendirmesiyle bebeğe Joubert Sendromu tanısı konuldu. Yenidoğan yoğunbakım ünitesinde genel durumunu bozmayan hiperpne-apne periyotları ara ara devam etti. Hood ile izlemlerinde kontrollü oral beslenme sonrasında da 1 haftalık süreçte sorun yaşanmayan bebeğin kafein sitrat tedavisi kesildi. 28 günlük takip ve tedavi sonunda anne uyumu tamamlanan bebek çocuk nöroloji takipleri yapılmak üzere önerilerle taburcu edildi. 


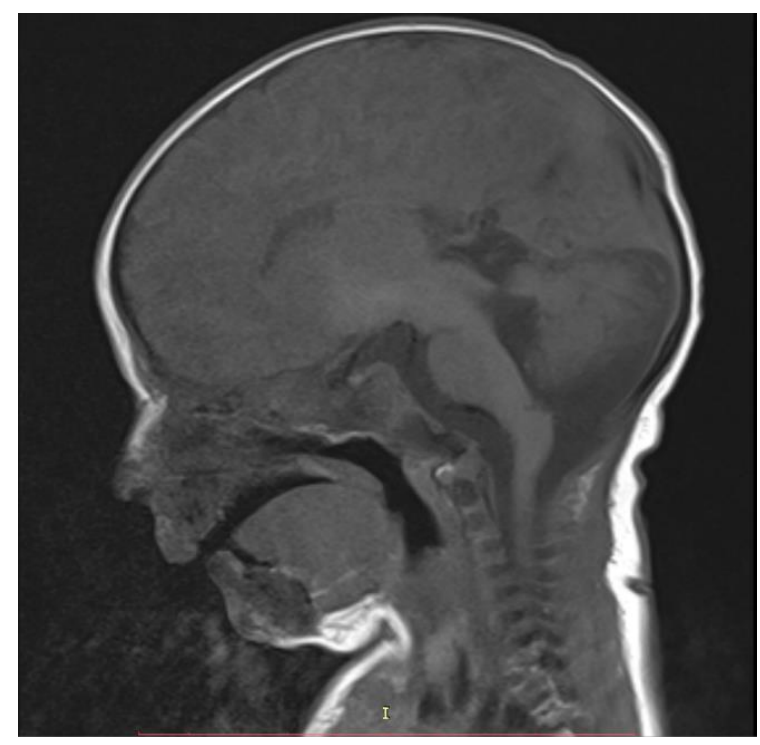

Resim 1. Agenesis of Corpus Collozum

\section{Tartışma}

JS sıklıkla yenidoğan döneminde prezente olan ancak tanı konulması ortalama 1-3 yaş sürelerine kadar gecikebilen otozomal resesif geçişli olduğu gösterilen bir hastalıktır. Görülme sıklığı 1/80000-1/100000 düzeylerindedir. Eşlik eden konjenital anormallikleri de içeren şekliyle Joubert ve ilişkili sendromlar olarak da adlandırılır $[6,7,8]$.

JS belirgin gelişim geriliği, ataksi ve hipotositeyle karakterize olup; yenidoğan döneminde anormal solunum paterni ve göz sorunları eşlik edebilir. Tanı daha çok kranial MR ile konulmaktadır. Tipik görüntüsü serebellar vermis aplazisi, üst pons ve isthmus seviyesinde derinleşmiş interpedinküler fossa ve kalın horizontal süperior serebellar pedinküllerdir $[9,10]$.

Joubert sendromunda fizik muayene ve klinik ile; hipertelorizm, geniş alın, pitozis, geniş ağız ve hipotonisite gibi bulgular saptanabilir. Solunum sistemi patolojileri sıklıkla hiperpne-apne periyodları ya da izole hiperpne epizotları şeklinde olabilmektedir $[11,12]$. En sık tutulan organların başında göz gelmekte olup, en sik sorun sıklıkla retina distrofisidir [13]. Gözün posteriolateral kısmını etkileyen bilateral ya da unilateral koloboma da görülebilir [14]. Khan ve ark. çalışmasında 6 vaka analizinde; kafa sallamalarla seyreden anormal göz hareketleri olan hastalarda ve pozisyonel nistagmusları olan hastalarda ayırıcı tanıda akılda tutulması gerektiği belirtildi [15]. Bizim hastamızda ışık refleksi bilateral alınıyordu, kırmızı refle testi pozitifti, haricinde bir problem saptanmadi. JS'lu hastalarda bifid ya da parçalı dil, polidaktili ve y şeklinde metakarpallar vardır [15]. Bizim hastamızda fizik muayenesinde kepçe kulak ve frontal belirginleşme haricinde ek bir özellik yoktu.

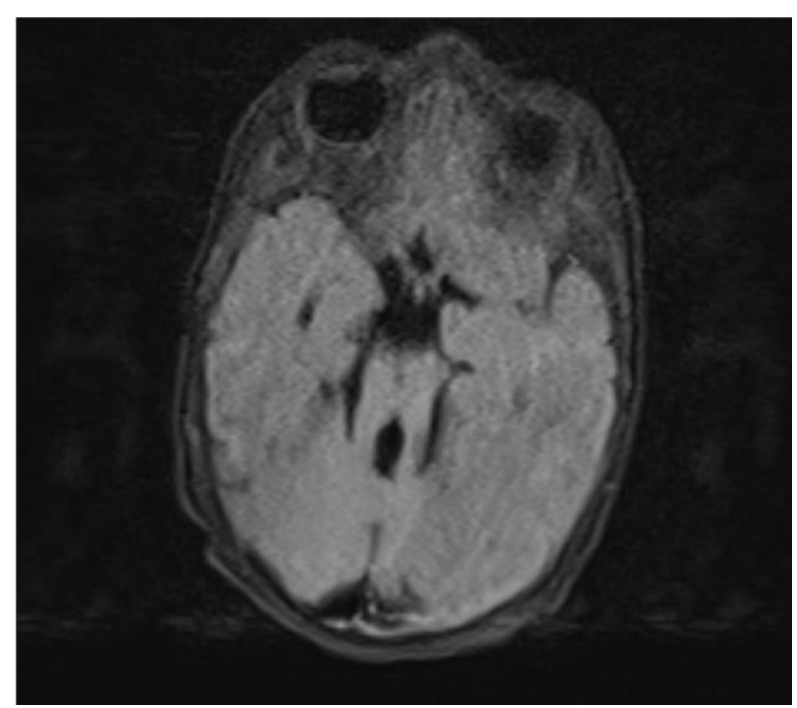

Resim 2. Thickened superior cerebellar pedicles around the elongated 4 th ventricle, molar tooth sign

Böbrek tutulumu hastaların \%25 ine eşlik etmektedir. Primer sorun kortikomedüller bileşkede oluşan kist kaynaklı olup tübülointersisyal hastalığa ve daha geç dönemde tanı konulanlar böbrek yetersizliği kliniği ile gelebilirler [16]. Karaciğer hastalığı erken gelişebilen hepatomegali ve konjenital hepatik fibroz olmakla birlikte kliniği karaciğer enzim düzeylerinde 2-3 kat artış ile olmaktadır. Geç dönem fark edilenler siroz ya da portal hipertansiyon şeklinde prezente olurlar [17]. Bizim hastamızda böbrek ve karaciğer fonksiyon testleri normaldi.

İskelet sistemi tutulumu s1kl1kla aksiyel polidaktili şeklinde olmaktadır, sıklığı \% 10-15 düzeylerindedir $[18,19]$. Barreirinho ve ark. 12 vakalık çalışmasının hepsinde ataksi, gelişim geriliği ve okülomotor anormallikler vardı [1]. Lubnan ve ark. çalışmasında yaygın hipotonisite ve CP tanısıyla takipli ve kontrol MR ında 18 aylık iken JS tanısı alan çocukların olduğu görülmüştür [20]. JS'nun klinik belirtileri neonatal dönemde başlamasına rağmen, tanı yaşı değişken fenotipi nedeniyle aylar y1llar sonra konulabilmektedir. Sıklıkla 1-3 yaşlarında ataksi ve oküler bulguların belirginleşmesi ile konulabilmektedir [9].

Rehman ve ark. 2009 yılındaki çalışmasında 13 aylık iken hipotonisite, apne ve gelişme geriliği sorunu olan çocuğa JS tanısı koymuşlar [21]. Haifa ve ark. (2016) 'da 5 günlük yenidoğan döneminde tanı koymuşlar [22]. Hastamıza postnatal 2. gününde tanısı koyuldu. Vakamızda düzensiz solunum şikâyeti postnatal 20. günde düzeldi. Gunzmann ve ark. (2007) çalışmasında yaygın hipotonisitesi olan 48 yaşındaki hastanın solunum problemleri başladıktan sonra ayırıcı tanıda akla gelmiş [23], Atsumi ve ark. (2008) yayımladıkları çalışmalarında 25. yaşında yaygın $\mathrm{CP}$ tanılı hastanın tekrarlayan uyku apneleri nedeniyle tanı almış vakası vardi [24]. 
Kranial MR görüntülemesinde "'molar diş görünümü', JS tanısı alan hastaların yaklaşık \% 85 oranında görünmektedir. Senior-Loken Sendromu, Varadi-Papp ve $\mathrm{COACH}$ (cerebellar vermis aplazisi, oligofrenia, ataksi, koloboma, hepatik fibroz) gibi bazı sendromlarda da molar diş görünümü olsa da eşlik eden ek patolojiler arasında farliliklar belirgindir. Varadi-Papp sendromunda daha çok dudak damak yarıklarının eşlik etmesi, $\mathrm{COACH}$ sendromunda ise solunum paterni bozukluklukları ve göz anormallikleri yokluğu ayırıcı tanıda önemlidir [25,26]. Hastamızda kranaial MR'da tipik molar diş görünümüne ek olarak hiperpne-apne periyotları JS açısından tanı koydurucu oldu.

Yenidoğan döneminde tanı konulan hastalarda solunumsal ve beslenme açısından sorun yaşanabilmektedir. Solunum düzensizliği sırasında mekanik ventilasyon desteği alan hastalarda tekrarlayan apneler nedeniyle oral beslenme geciktirilmeli, olas aspirasyon riskleri minimize edilmelidir. Hastamiz postnatal 2. gün tanı alıp 20 gün nasal CPAP' da sonrasinda postnatal 28. Gün apnelerinin tekrarlamaması üzerine taburcu edildi.

\section{Sonuç}

Sonuç olarak sıklıkla ileri yaşlarda belirgin nörolojik defisitler geliştikten sonra tanı alan bu hasta grubunda, yenidoğan döneminde tekrarlayan apneler ve solunum düzensizliği ile giden hastalarda erken sepsis ve solunum problemleri dişlandıktan sonra erken aşamada kranial MR çekilmeli ve bu hasta grubunda JS akılda tutulmalıdır

\section{Referanslar}

1. Barreirinho, MS, Texeira, J, Moeira, NC, CalcadaBastos, S Goncalvaz, S, Barbot, MC, JoubertSyndrome report of 12 cases. Review Neuroogyl, 2001, 32(9), 812-817

2. Bozaykut, A, Atay, E, Özdü, İI, Atay, Z, Uygur, N, Gülsever, N, Joubert sendromlu bir yenidoğan. Göztepe Tip Dergisi, 2002, 17 , 245-246

3. Paksu, MŞ, Dağdemir, A, Taşdemir, HA, Güngör, O, Küçüködük, Ş, İncesu, L, Jubert sendromu; olgu sunumu. OMÜ Tip Dergisi, 2004, 21(2), 90-93.

4. Aslan, H, Ulker, V, Gulcan, E,M, Numanoglu, C, Gul, A, Agar, M, Ark, H,C, Prenatal diagnosis of Joubert syndrome: a casereport. Prenatal Diagnosis, 2002, 22, 13-16.

5. Maria, B,L, Boltshauser, E, Palmer, S,C, Tran, T,X, Clinica features and revised diagnostic criteria in Joubert Syndrome. Journal of Child Neurology, 1999, 14(9), 583-590.

6. Maria, BL, Quisling, RG, Rosainz, LC, Yachnis, AT, Gitten, J, Dede, D, Molartoothsign in Joubert syndrome clinical, radiologic and pathologic significance. Journal of Child Neurology, 1999 14(6), 368-76.

7. Ferland, RJ, Eyaid, W, Collura, RV, Tully, LD, Hill, RS, Al-Nouri, $\mathrm{D}$, et al. Abnormal cerebellar development and axonal decussation due to mutation in AHI1 in Joubert syndrome. Nature Genetics, 2004, 36, 1008-1013

8. Andermann, F, Andermann, E, Ptito, A, Fontaine, S, Joubert, M History of Joubertsyndromeand a 30-year follow up of the origina proband. Journal of Child Neurology, 1999, 14(9), 565-9,

9. Akcakus, M, Gunes, T, Kumandas, S, Kurtoglu, S, Coskun, A. Joubert syndrome: Report of a neonatal case. Paediatric Child Health, 2003, 8(8), 499-502.

10. Parisi, MA, Doherty, D, Chance, PF, Glass, IA, Joubert syndrome (and related disorders). European Journal of Human Genetics, $2007,15(5), 511-521$.
11. Joubert, M, Eisenring, J, J, Robb, JP, Andermann, F. Familial agenesis of the vermis: a syndrome of episodic hyperpnoea, abnormal eye movements, ataxia, and retardation. Neurology, 1969, 19(5), 813-825.

12. Brancati, F, Dallapiccola, B, Valente, E, M, Joubert syndrome and related disorders. Orphanet Journal of Rare Diseases, 2010, 5, 20.

13. Khan, AO, Oystreck, DT, Seidahmed, MZ, AlDrees, A, Elmalik, SA, Alorainy, IA, Salih, MA, Ophthalmic features of Jouber syndrome. Ophthalmology, 2008, 115, 2286-2289.

14. Gregory-Evans, CY, Williams, MJ, Halford, S, Gregory-Evans, K, Ocular coloboma: a reassessment in the age of molecular neuroscience. Journal of Medical Genetics, 2004, 41, 881-891.

15. Chodirker, BN, Shah, NS, Bunge, MK, Reed, MH, Another case of Varadi-Papp Syndrome with a molar tooth sign. American Journal of Medical Genetics A, 2005, 136, 416-417.

16. Salomon, R, Saunier, S, Niaudet, P, Nephronophthisis. Pediatric Nephrology, 2009, 24, 2333-2344.

17. Desmet, VJ, Congenital diseases of intrahepatic bile ducts: variations on the theme "ductal plate malformation". Hepatology, 1992, 16 1069-1083

18. Chance, PF, Cavalier, L, Satran, D, Pellegrino, JE, Koenig, M, Dobyns, WB, Clinical nosologic and genetic aspects of Joubert and related syndromes. Journal of Child Neurology, 1999, 14: 660-666.

19. Pellegrino, JE, Lensch, MW, Muenke, M, Chance, PF, Clinical and molecular analysis in Joubert syndrome. American Journal of Medical Genetics, 1997, 72, 59-62.

20. Lubna, H. Dekair, MBBS, Hussein Kamel, FRCR, Haitham, O, ElBashir, Joubert syndrome labeled as hypotonic cerebral palsy. Neurosciences (Riyadh) 2014, 19(3), 233-235.

21. Rehman, Iu, Bett, Z, Husen, Y, Akhtar, AS, Khan, F,A, The 'molar tooth sign' in Joubert syndrome. J Pak Med Assoc, 2009, 59(12), 851-3.

22. Haifa, ABD, Abdul-Hakeem, MBM, Zain, H,A, Joubert syndrome in a neonate: case report with literature review. Sudan J Paediatr 2016, 16(1), 53-57.

23. Gunzler, SA, Stoessl, AJ, Egan, RA, Weleber, RG, Wang, P, Nutt, JG, Joubert syndrome surviving to adulthood associated with a progressive movement disorder. Movement Disorders, 2007, 22 262-265.

24. Atsumi, M, Takeda, T, Misaki, Y, Ogata, H, [Joubert syndrome diagnosed based on sleep disordered breathing in 25-year-old man-case report]. Brain Nerve, 2008, 60, 195-198.

25. Barzilai, M, Ish-Shalom, N, Lerner, A, Iancu, TC, Imaging findings in COACH syndrome. American Journal of Roentgenology, 1998, 170, 1081-1082.

26. Van Beek, EJ, Majoie, CB, Joubert syndrome. Radiology, 2000, 216 , 379-382.

http://edergi.cbu.edu.tr/ojs/index.php/cbusbed isimli yazarın CBU-SBED başlıklı eseri bu Creative Commons Alıntı-Gayriticari4.0 Uluslararası Lisansı ile lisanslanmıştır.

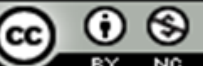

